\title{
DEBATES
}

\section{Relações bilaterais Brasil-Haiti: o caso da alteridade nos discursos presidenciais e nas politicas educacionais}

\author{
Brazil-Haiti bilateral relations: the case of alterity in presidential \\ speeches and educational policies
}

\section{Daniela Dos Santos Caetano Sandra Fernandes Leite}

\section{Resumo}

As relaçóes bilaterais Brasil-Haiti tiveram maior densidade com a liderança brasileira na Missão das Nações Unidas para Estabilização do Haiti. Em face desta realidade, este trabalho se interroga sobre quais são as possíveis compreensóes acerca do conceito de alteridade como elemento de análise da política externa educacional conduzida pelo Brasil no Haiti? O objetivo central busca compreender a construçáo de sentidos acerca do outro, para tanto se torna crucial conhecer e interpretar os discursos e analisar as políticas educacionais, a fim de constatar possibilidades de materialização da alteridade enquanto percepção do outro e de suas demandas. A metodologia adotada foi a análise do discurso e a pesquisa documental. Concluiu-se que a alteridade para além de simplesmente enxergar o outro requer solidariedade, emancipação e proteção dos direitos humanos fundamentais.

\section{Palavras-chave}

Relações Internacionais; Alteridade; Análise de Discurso; Política Educacional.

\begin{abstract}
Brazil-Haiti bilateral relations became denser with the Brazilian leadership of the United Nations Stabilization Mission in Haiti. In face of this reality, this paper inquires about the possible understandings of the concept of otherness as an element of analysis of the foreign educational policy conducted by Brazil in Haiti. The central objective is to understand the construction of meanings about the other, so it becomes crucial to know and interpret the discourses and analyze educational policies in order to verify possibilities of materialization of otherness as the perception of the other and their demands. The methodology adopted was discourse analysis and documentary research. It was concluded that alterity beyond simply seeing the other requires solidarity, emancipation and the protection of fundamental human rights.
\end{abstract}

\section{Keywords}

International Relations; Otherness; Discourse Analysis; Educational Policy. 
144 | Daniela Dos Santos Caetano e Sandra Fernandes Leite

\section{Introdução}

A política externa brasileira nos governos Luiz Inácio Lula da Silva (20032010) e Dilma Vana Rousseff (2011-2016) foram preponderantes no trato das relações internacionais adotado pelo país nos 13 anos de governo do Partido dos Trabalhadores (PT). Por outro lado, com o impeachment sofrido pela presidenta Dilma Rousseff e, por conseguinte, o empossamento de Michel Miguel Elias Temer Lulia na chefia do Governo Federal, a dinâmica da política externa adotou novos contornos, dos quais se destaca nesta composição o caso das relações bilaterais BrasilHaiti em decorrência da Missão das Nações Unidas para Estabilização do Haiti (Minustah) em 2004 e seu encerramento em 2017.

Em face desta realidade, este trabalho se interroga sobre quais são as possíveis compreensôes acerca do conceito de alteridade como categoria de análise da política externa educacional conduzida pelo Brasil no Haiti no período de atuação da Minustah (2004-2017)?

Segundo o Dicionário de Filosofia Nicola Abbagnano (2007, p. 34) alteridade significa "ser outro, colocar-se ou constituir-se como outro (...)", ou seja, do reconhecer o outro em sua diversidade e se colocar em seu lugar por meio da empatia, do respeito e da solidariedade. Para Franco (2000) o outro num mundo marcado por problemas de diferentes ordens, sociais, econômicas, políticas, culturais, entre outras, passa a ter centralidade nas ciências sociais, nos projetos de solidariedade e cooperação (FRANCO, 2000). A autora expõe que a comparação de si com o outro é inevitável, levando ao estabelecimento de categorias que permitem confrontar diferenças e igualdades.

Prospere e Nogaro, ao abordarem a questão da educação e da transformação social no Haiti, empregam dois conceitos: alteridade e outridade. E explicam que educar para a vida exige atitudes de percepção, captação e de reconhecimento do outro em sua totalidade de condição humana e ser no mundo (PROSPERE e NOGARO, 2017). Uma reflexão oposta ao conceito de alteridade consiste no fato de querer submeter o outro, dominá-lo, “(...) a colonialidade do outro é uma prerrogativa que permanece até os nossos dias, até porque a estrutura das nossas sociedades ocidentais deixa como herança este querer colonizar o outro" (PROSPERE e NOGARO, 2017, p. 28).

Nesta composição o conceito de alteridade será elaborado pelo reconhecimento e respeito ao outro, valendo-se também dessas elaborações para refletir sobre si mesmo, tomando como elemento de análise os enunciados relativos às 
práticas de alteridade entre Brasil e Haiti, buscando entender mecanismos de solidariedade, cooperaçáo e o direito à educação.

O objetivo central deste artigo consiste em compreender a construção de sentidos acerca do outro, manifestados nos discursos presidenciais e materializados na condução de determinadas políticas educacionais. Para tanto seus objetivos específicos consistem em: conhecer as resenhas disponibilizadas no site do Ministério das Relaçôes Exteriores (MRE) para interpretar a manifestação de temas relativos à alteridade nos discursos presidenciais durante o período de 2004 a 2016; analisar a política educacional concebida pelos acordos internacionais assumidos pelos dois países (Brasil e Haiti) e constatar possibilidades de materialização da alteridade enquanto percepção do outro e de suas demandas.

A metodologia adotada condiz com a análise do discurso como método de interpretação e produção de sentidos, pautada nas considerações teóricometodológicas de Pêcheux (2006) e Orlandi (2005) e a pesquisa documental pautada nas elaborações de Lüdke e André (1986), Sá-Silva, Almeida e Guindani (2009).

Para elaboração de tal proposição recorremos a uma breve contextualização histórica da política externa brasileira nos períodos dos governos Lula, Dilma e Michel Temer, à elaboração metodológica do estudo, à análise do material e às considerações finais.

\section{Contextos da politica externa e das relações Brasil-Haiti}

Após a Segunda Guerra Mundial, empreendeu-se uma nova forma de relacionamento e de dinâmica entre os países, a Cooperação Internacional para o Desenvolvimento (CID), que num primeiro momento esteve mais próxima da atuação isolada com vistas a responder uma situação problema de determinada nação para, num segundo momento, se aproximar de modelos mais integrados às diferentes demandas e potencialidades dos países com vistas ao desenvolvimento em diferentes setores, ao bem-estar e à promoção de um relacionamento mundial mais equânime.

No que tange à CID, Milani (2012, p. 211) define que pode ser entendida como um sistema que articula a política dos Estados e atores não governamentais, bem como um conjunto de normas difundidas e prescritas por organizaçóes internacionais que creem que o desenvolvimento em bases solidárias seria uma solução desejável para as contradições e as desigualdades geradas pelo capitalismo no plano internacional. Dentre as possibilidades de se compreender os campos de 
atuação da CID e seus contextos, atualmente encontram-se as políticas realizadas pela Cooperação Norte-Sul (CNS) e as políticas realizadas pela Cooperação Sul-Sul (CSS) , no qual a primeira se refere aos países do norte considerados desenvolvidos, centralizadores e hegemônicos, enquanto a segunda se refere aos países do sul, considerados emergentes, periféricos e diversos.

Por sua vez, Caixeta (2015, p. 4) aponta dois fenômenos no cenário de abrangência global que visam propor novos paradigmas de desenvolvimento: a cooperação Sul-Sul e as epistemologias do Sul. Para a autora, no campo da episteme, os estudos realizados com a proposta de se teorizar a partir do local sul sáo plurais ao ponto de não constituírem uma única teoria, assim como tiveram raízes nos pensamentos orientais, pós-coloniais, subalternos, pós-ocidentalistas, da geopolítica do conhecimento, do pensamento de fronteira e pós-modernos (CAIXETA, 2015, p. 11).

No caso do Brasil, as primeiras décadas do século XXI foram preponderantes para que o país se configurasse numa potência significativa no âmbito das relações Sul-Sul (como país membro do BRICS, por exemplo) ${ }^{1}$ e numa liderança regional (América do Sul e Caribe), ambas dimensões mediadas pelas políticas de cooperação Sul-Sul. No tocante da cooperação regional se destacou na vigorosa atuação com o Mercado Comum do Sul (Mercosul) com a criação do Fundo para a Convergência Estrutural do Mercosul (FOCEM) em 2005, na formação da Cúpula BrasilComunidade do Caribe (CARICOM) em 2010 e na criação da Comunidade de Estados Latino-Americanos e Caribenhos (CELAC) em decorrência da fusão entre a Cúpula de Chefes de Estado e de Governo da América Latina e Caribe sobre Integração e Desenvolvimento (CALC) e o Grupo do Rio (GRIO), em dezembro de 2011.

Nos mandatos presidenciais do governo Luiz Inácio Lula da Silva (2003 a 2010) e do governo Dilma Vana Rousseff (2011 a 2016), a tônica da Política Externa Brasileira (PEB) consistiu de sobremaneira no fortalecimento e ampliação das relaçóes de cooperaçáo, nas quais o país assumia um papel de protagonista frente à economia nacional e internacional emergente e à defesa das pautas sociais.

Segundo Sá (2015), vários fatores colaboraram para a retomada de uma PEB mais assertiva, dentre os quais se destacam o fim da ditadura militar, a consolidação

\footnotetext{
${ }^{1}$ As siglas correspondem aos membros do grupo econômico de países emergentes: Brasil, Rússia, Índia e China e África Do Sul.
} 
da democracia no país, o crescimento socioeconômico, a maior capacidade de investimento e açáo do Estado, e a estabilidade dos fundamentos macroeconômicos.

Outrossim, o fato do Brasil ter atuado como país membro não permanente do Conselho de Segurança das Nações Unidas (CSNU) e por aceitar liderar a Minustah, segundo a Resolução n. 1542 de 29 de fevereiro de 2004, corroboraram para uma nova postura frente ao Haiti e ao mundo.

Segundo Kenkel (2011, p. 24) a participação do Brasil na Minustah representou uma redefinição na identidade do país, voltada para uma atuação global, com foco na análise custo-benefício, visando aumentar sua influência internacional. E reforça que essa mudança de autoidentificaçáo centrada numa natureza emergente disposta e preparada para assumir as agendas e compromissos internacionais culminou no afastamento dos favorecidos pelo contexto regional para a aproximação daqueles cuja busca e apoio são vistos como voltados a uma maior retribuição final a nível internacional (KENKEL, 2011, p. 24-25).

Sobre tais fatos, Miyamoto pontuou que as diretrizes da política externa brasileira da época apresentaram como características marcantes a atuação internacional centrada na figura do Presidente da República; a busca por um lugar de realce no contexto internacional a qualquer preço; demanda por cargos de prestígio no âmbito das decisões mundiais; a tentativa de consolidação enquanto líder regional; tentativa de mostrar capacidade como agente intermediador de conflitos e de resolução de problemas que afetam outros países, daí a forte presença em cenários como o Haiti (antes e pós-terremoto), dentre outras (MIYAMOTO, 2011).

Com a chegada de Michel Temer no poder em 31 de agosto de 2016, o papel de centralidade do presidente da república se dissolve, bem como dos interesses políticos estabelecidos nos governos petistas. Segundo Nunes e Rodriguez (2017) há claras mudanças em relaçáo ao governo anterior, das quais se destacam a nomeação de José Serra para o Ministério das Relaçóes Exteriores em vez de um profissional de carreira preparado para exercer a função de diplomata, ou seja, aprovado no Concurso de Admissão do Instituto Rio Branco (IRBR), o que representou a quebra de uma tradição e, também a definição de novos pilares para a política internacional respaldada em dez novas diretrizes da política externa brasileira (NUNES e RODRIGUEZ, 2017).

Os autores pontuam que diferentemente da política Lula/ Dilma, a transição da política Dilma/Temer ocasionou no declínio da PEB, mesmo estando a política externa de Dilma Rousseff em certo grau de queda devido aos reflexos da crise 
econômica, no governo de Michel Temer o declínio da política externa se agravou e se acentuou, marcando visceralmente a condução entre um governo e outro (NUNES e RODRIGUEZ, 2017).

A ênfase de outrora dirigida às políticas de cooperação Sul-Sul predominantes no governo Lula-Dilma se reconfigurou “(...) de uma atuação pró-ativa para outra que parece ser de realinhamento automático e de pouca crítica ao centro hegemônico geopolítico e capitalista internacional" (PENNAFORTE, 2017, p. 2).

Marcada por fortes atribulações políticas, a intervenção da ONU liderada pelo Brasil no Haiti gerou entendimentos e consequências diferentes do que se espera para uma missão de estabilização e paz. A visão de estudiosos haitianos sobre a questão revela que a Minustah não contribuiu para o efetivo desenvolvimento do país e para o reestabelecimento de um estado democrático de direitos. Houve diversas denúncias de abusos de poder e desvio de verbas por parte dos responsáveis por manter a segurança da população e as entidades responsáveis pela redistribuição da ajuda humanitária, assim como se agravou o clima austero entre haitianos e estrangeiros ligados à missão de paz no país.

Seguy argumenta que as políticas internacionais aplicadas nas sociedades onde vigem intervenções estrangeiras não correspondem à promoção do desenvolvimento, a democracia e soberania nacional, ao contrário, volta-se para conformação desta sociedade à visão ocidental de mundo" a alteridade do pensamento moderno/colonial não deixa nenhum espaço para a diversidade/diferença, o Haiti é assim conduzido a escolher entre resistir, assimilar-se ou aniquilar-se" (SEGUY, 2014, p. 82-83).

A própria história do Haiti remonta de um passado de luta contra o colonialismo e a escravização. Ao se rememorar a história e a luta pela independência do país, constata-se que o país influenciou mentalidades e decisões, principalmente por atuar tanto no imaginário dos escravagistas, quanto dos povos escravizados, devido ao fato de ser a primeira república negra a romper com o domínio europeu em 1804 . 
Haiti se tornou a primeira república negra fora do continente africano, e na segunda sociedade pós-colonial da era moderna (depois dos Estados Unidos). No processo, os ex-escravos - seus exércitos, seus líderes, seus guerrilheiros - derrotaram os exércitos invasores da Inglaterra, Espanha e França (...) Os senhores europeus foram derrotados por seus servos africanos em uma reviravolta sem precedentes dos destinos raciais. Os proprietários de escravos entendiam, e temiam as consequências do que aconteceu no Haiti. Deste modo se materializou, num contexto explosivo de rivalidades internacionais, confrontos raciais e lutas ideológicas, o pior pesadelo dos produtores; a dos escravos senhores de sua própria igualdade, armados e capazes de derrotar ao mesmo tempo os produtores e o governo colonial (JAMES, 2003, p. 14) ${ }^{2}$.

No entanto, após a independência o país enfrentou desafios incomensuráveis, tais como pagamento de tributos para a França, invasão estadunidense e sucessivas intervenções sob a tutela de missões da ONU. A última e mais recente missão foi a Minustah, composta por grande efetivo militar e liderada pelo Brasil.

Para Seguy (2014) o processo que se realiza de dominação militar de um país periférico por outro país de periferia, mas com ligações ou relações de subordinação com o centro corresponde a uma nova forma de colonialismo.

\footnotetext{
${ }^{2}$ Haití se convirtió en la primera república negra fuera del continente africano, y en la segunda sociedad poscolonial de la era moderna (después de los Estados Unidos). En el proceso los ex esclavos — sus ejércitos, sus líderes, sus guerrillas — habían derrotado a los ejércitos invasores de Inglaterra, España y Francia (...) Los dueños europeos habían sido derrotados por sus siervos africanos en un vuelco sin precedentes de los destinos raciales. Los propietarios de esclavos comprendieron, y temieron, las consecuencias de lo acontecido en Haití. De este modo se materializó, en un contexto explosivo de rivalidades internacionales, enfrentamientos raciales y luchas ideológicas, la peor pesadilla de los plantadores; la de unos esclavos dueños de su propia igualdad, armados y capaces de derrocar al mismo tiempo a los plantadores y al gobierno colonial.
} 
(...) o colonialismo oficialmente acabou para que a colonialidade, a lógica, a concepção colonial seja reforçada. As administraçóes autoritárias dos países centrais não existem mais para exercer seu controle direto nas periferias, porém, os controles indiretos sobre os Estados-naçóes da periferia - o neocolonialismo - não perderam nada de sua eficiência (...) (SEGUY, 2014, p. 101).

Carvalho e Rosa explicitam que o Brasil enquanto país emergente procurou elaborar uma política externa baseada também na solidariedade aos países mais necessitados e no fortalecimento das relações com os países vizinhos (CARVALHO e ROSA, 2011, p. 488).

Esta compreensão da política externa brasileira e seus feitos, no caso em questáo a condução da Minustah, abre precedentes para se pensar as contradiçóes e os conflitos suscitados no bojo das relações Brasil-Haiti, principalmente porque a missão permaneceu em vigência por mais de uma década, treze anos, nos quais ambos os países conviveram de maneira direta e/ou indiretamente.

\section{O outro é o Haiti, "o outro" somos nós: questões teórico- metodológicas}

No estudo em questão, a metodologia adotada se respaldou na análise do discurso e na pesquisa documental.

A análise do discurso, como método de estudo das ciências humanas revela a importância da linguagem enquanto fio condutor das relaçôes em seus diferentes aspectos. Outra importância consiste no fato de que o discurso tomado como objeto de estudo deflagra tanto os seus contextos de produção, quanto elementos importantes da interação humana mediados pela comunicação.

Orlandi expõe que a palavra discurso em sua origem etimológica denota o curso, percurso, a palavra em movimento ou a prática da linguagem e com seu estudo é possível observar o homem falando (ORLANDI, 2005, p. 15).

No âmbito da palavra em movimento, Pêcheux (2006) elucida que o discurso se compõe de acontecimento histórico e acontecimento discursivo, onde a memória de determinado enunciado se ressignifica na medida em que toma uma nova realidade como seu contexto de produção. Assim, ao se ater a análise do discurso de linha francesa, aponta que todo discurso é passível de descrição e, por conseguinte de interpretação, pois considera a presença do outro. 
E é neste ponto que se encontra a questão das disciplinas de interpretação: é porque há o outro nas sociedades e na história, correspondente a esse outro próprio ao linguajeiro discursivo, que aí pode haver ligação, identificação ou transferência, isto é, existência de uma relação abrindo a possibilidade de interpretar. E é porque há essa ligação que as filiaçôes históricas podem- se organizar em memórias, e as relaçôes sociais em redes de significantes (PECCHEUX, 2006, p. 54, grifo do autor).

Para Pêcheux (2006) o discurso não se descola de uma dada realidade sóciohistórica, tampouco pode ser analisado de maneira abstrata e/ou simplesmente pela incidência de repetiçôes. É preciso que o processo de análise não submeta o discurso a uma sequência de enunciados que desconsiderem o acontecimento, o fato discursivo enquanto elemento de produção real e que, por outro lado, conceba- se o discurso em sua dimensão transformadora, levando em consideração as diferentes possibilidades de ressignificação.

Retomando as ponderações de Orlandi, sobre o método, cabe destacar a importância da interpretação como dispositivo de análise do discurso. Pontua-se que a interpretação permite colocar em evidência o dito em relação ao não dito "procurando ouvir, naquilo que o sujeito diz aquilo que ele não diz, mas que constitui igualmente os sentidos de suas palavras" (ORLANDI, 2005, p. 59).

Para alcançar uma análise satisfatória segundo Orlandi, será preciso percorrer três etapas que consistem na passagem da superfície linguística (material em estado bruto, textos) para o objeto discursivo (objeto teorizado produzido do primeiro contato do analista com o material em estado bruto) e da passagem do objeto discursivo para o processo discursivo (etapa constituída da passagem das suposições e hipóteses iniciais para a relação com a ideologia e a formação de sentidos). Para a autora é no trabalho dessas etapas da análise que o analista observa os efeitos da língua na ideologia e a materialização desta na língua (ORLANDI, 2005, p. 68).

A análise documental permite conhecer os discursos presidenciais proferidos às tropas da Minustah, aos governantes do Haiti e à população haitiana, publicados no acervo Resenhas da Política Exterior no Brasil e, por conseguinte, os Atos Internacionais assinados pelo Brasil e pelo Haiti, disponibilizados na Plataforma Concórdia, ambos encontrados no site do Itamaraty³.

3 Conhecido também como Ministério das Relaçôes Exteriores. Disponível em: <http://www.itamaraty.gov.br/pt-BR>. Acesso em 10 de jun. de 2018. 
No tocante da pesquisa documental, Lüdke e André elaboram que embora a análise documental seja pouco explorada nos estudos relativos à educação, pode vir a constituir uma importante técnica seja para complementar outras técnicas, seja para desvelar novos aspectos de um tema ou problema (LÜDKE e ANDRÉ, 1986, p. 38).

As autoras compreendem a análise documental enquanto técnica e expõem que os documentos constituem uma importante fonte de informação que surge em determinado contexto onde o pesquisador pode retirar evidências que fundamentem suas declarações (LÜDKE e ANDRÉ, 1986, p. 39).

Por pesquisa documental se entende a conjunçáo e o atravessamento de diferentes métodos, procedimentos e técnicas que tenham como base compreender a dimensão do documento enquanto possibilidade investigativa para apreensão de dada realidade, ou conceito.

Sá-Silva, Almeida e Guindani apontam que a “(...) pesquisa documental é um procedimento que se utiliza de métodos e técnicas para a apreensão, compreensão e análise de documentos dos mais variados tipos" (SÁ-SILVA, ALMEIDA e GUINDANI, 2009, p. 5). E ressaltam que pesquisa documental corresponde ao estudo de materiais que ainda não receberam trato analítico, ou seja, as fontes primárias (SÁ-SILVA, ALMEIDA e GUINDANI, 2009, p. 6).

Evidencia-se que diferentemente de Lüdke e André (1986), dentre outros que recomendam a investigação do conteúdo para o estudo de documentos, utilizou-se como método a análise do discurso.

\section{Discursos presidenciais}

Em busca no site do MRE, encontrou-se na seção Resenhas de Política Exterior do Brasil, um acervo com 43 resenhas, começando da primeira publicação n. 77 do segundo semestre de 1995 e finalizando com a última publicação n. 119 correspondente ao segundo semestre de 2016. Selecionou-se como objeto de estudo 26 resenhas correspondentes aos períodos de 2004 a 2016, período em que o Brasil atuou no Haiti liderando a Minustah.

Apesar de a publicação ser estruturada com textos diversos como discursos, acordos, comunicados, memorandos, artigos, notas e entrevistas, esta proposta se ateve aos discursos presidenciais voltados tanto para os integrantes da Minustah, quanto para representantes políticos do Haiti, ou o povo haitiano, buscando enunciados que apresentassem a questão da alteridade. 
Descartou-se 22 resenhas, pois mesmo havendo diferentes mençóes sobre o Haiti por parte dos ministros das Relações Exteriores e até pelo presidente e pela presidenta em discursos realizados em outros países, grupos de cooperação regional, ou no CSNU, os destinatários e as situações não foram condizentes com a proposta desta composição.

Foram selecionadas quatro resenhas cujos discursos presidenciais se voltavam para as tropas da Minustah, ou diretamente para representantes políticos ou o povo haitiano.

A primeira Resenha selecionada foi a de n. 94, correspondente ao primeiro semestre de 2004. Esta publicação contou com vários textos no quais o Haiti foi mencionado, no entanto o objeto de análise consistiu no discurso do Presidente Luiz Inácio Lula da Silva de 31 de maio de 2004, intitulado de "Missão de Paz no Haiti", a despeito da cerimônia de embarque das tropas militares para missão de paz.

Neste discurso o Presidente Luiz Inácio Lula da Silva, expóe que o país sente orgulho e satisfação por comandar a missão de paz, bem como na disponibilidade e preparo das forças armadas em ajudar um país irmáo. Sobre o Haiti, o presidente apresenta que se trata do terceiro país com a maior população negra nas Américas e sobre este fato, afirma que o Brasil também compartilha dessa herança africana e, por isso, não poderia ficar indiferente diante dos problemas que o povo haitiano está enfrentando (SILVA, 2004a, p. 139).

Cita-se o fato de que se posicionar e atuar na missão de paz, também representa uma forma de exercer responsabilidade no cenário internacional, assim, “(...) Como membro do Conselho de Segurança, o Brasil buscou refletir as preocupaçôes de nossa região e interpretar os interesses do povo haitiano e da comunidade internacional" (SILVA, 2004a, p.140).

O discurso aponta como tarefa principal da missão, o reestabelecimento da democracia no Haiti, considerado um país irmão.

A segunda resenha foi a de n. 95 relativa ao segundo semestre de 2004. Nesta publicação, há diferentes assuntos referentes ao Haiti, porém serão apresentados dois textos.

O primeiro se intitula de "A visita do Presidente da República ao Haiti e com o discurso do Presidente da República, Luiz Inácio Lula da Silva, perante a Brigada Brasil da Missão das Naçóes Unidas para o Haiti, em Porto Príncipe, Haiti, em 18 de agosto de 2004". Neste o presidente Luiz Inácio Lula da Silva, relata que pela primeira vez um presidente brasileiro pisa em solo haitiano, país com que o Brasil 
compartilha de sua herança africana (SILVA, 2004b, p. 65). Menciona-se o fato de que em reuniáo com líderes caribenhos e centro-americanos em virtude da posse do presidente da República Dominicana e do presidente Boniface Alexandre do Haiti, discutiu-se a necessidade de grande empenho para o progresso institucional, social e econômico do Haiti. Destaca-se a contribuição do Brasil em termos de cooperação com projetos envolvendo a saúde, a agricultura familiar, a infraestrutura e o transporte urbano. Para finalizar, externa-se que o presidente do Brasil está acompanhado do presidente do Uruguai e que em virtude de um jogo de futebol entre a seleção brasileira e a seleção haitiana, espera-se que se estreitem as relaçốes de amizade e contato entre ambos os países.

No segundo texto, explicita- se que o objetivo da visita do presidente do Brasil ao Haiti é a celebração da paz, bem como se elucida que o envio das tropas ao país se deve ao acolhimento do chamado do CSNU, pois é o órgão da ONU que opera em favor da paz e da segurança internacional. Outro fator importante condiz com a declaração de que o Brasil está solidário com o Haiti e espera que o país supere as dificuldades e volte a ser uma nação "(...) que inspirou gerações e produziu heróis. Queremos que o Haiti volte a levantar-se em defesa de seu destino" (SILVA, 2004c, p. 66). Salienta-se o desejo de ajudar o país a se reconstruir, assim como do desejo de que "(...) os haitianos sintam que podem contar com a amizade e a solidariedade do povo brasileiro e de meu governo" (SILVA, 2004c, p. 66).

A terceira resenha selecionada foi a de no 106 do primeiro semestre de 2010, cujos discursos incidem os militares mortos devido à tragédia ocasionada pelo terremoto de 12 de janeiro de 2010 no Haiti e a formatura das tropas brasileiras na Minustah. Foram proferidos dois discursos, o primeiro no hangar da base aérea em Brasília e o segundo na capital do Haiti, Porto Príncipe, em 25 de dezembro de 2010.

O primeiro discurso "Cerimônia de honras fúnebres aos militares mortos no cumprimento do dever na Missão de Paz no Haiti”, apresenta o pesar pelo sofrimento que se abateu devido às mortes causadas pelo terremoto, conforme expressa Silva (2010a, p. 51) "Nosso coração, que já estava partido pelo sofrimento desse povoirmão, de raízes africanas como as nossas, recobriu- se duplamente de luto e dor nos dias que se seguiram". Externa-se que do total de mortes, vinte brasileiros tiveram a vida interrompida em decorrência do terremoto.

O segundo discurso "Cerimônia de formatura das tropas brasileiras da Missão da ONU no Haiti (Minustah)", elaborou sobre a necessidade de reconstrução do país, que além de passar por situações limiares em relação às condiçóes de vida digna e plena, passou a enfrentar uma realidade pautada na subvida. Sobre a ajuda 
humanitária, relata-se que o país contribuirá com alimentos, medicamentos, água potável, médicos e voluntários (SILVA, 2010b, p.84).

A quarta e última resenha escolhida foi a de $\mathrm{n}^{\mathrm{o}} 110$ do primeiro semestre de 2012. Nesta publicação há o primeiro discurso da presidenta Dilma Vana Rousseff, intitulado de "Discurso da Presidenta da República, Dilma Rousseff, durante cerimônia de apresentação do contingente brasileiro da Missão das Nações Unidas para a Estabilização do Haiti”, na capital Porto Príncipe, Haiti, em 01 de fevereiro de 2012. A presidenta começa agradecendo aos presentes e se dirigindo aos brasileiros e trabalhadores haitianos presentes na base militar. Declara-se que a presença da Minustah além de refletir o compromisso e a amizade entre os dois países, busca dar um novo sentido as missóes de paz da ONU, elaborando sobre a necessidade primeira de proteger. Expóe-se a importância de se pautar a solidariedade tanto relativa ao governo brasileiro, quanto à comunidade internacional e, finaliza-se explicitando que embora o Brasil auxilie o país, cabe ao próprio, nas palavras de Rousseff (2012, p. 26) “(...) definir as prioridades de seu povo e a melhor maneira de canalizar a ajuda internacional (...)”, para que assim seja possível no futuro a substituição da Minustah por instituiçôes nacionais.

No que condiz com o mandato de Michel Temer não há nenhum discurso presidencial dirigido à população haitiana, tampouco às tropas brasileiras da Minustah, mesmo tendo sido realizado o encerramento da missão em seu governo. Neste caso, o não dito se revela como importante elemento de análise, pois revela o distanciamento do governo atual com os pressupostos estabelecidos nos governos anteriores.

Os discursos presidências nos mandatos Lula e Dilma também se diferenciaram na medida em que os primeiros discursos estavam carregados de um apelo relativo às semelhanças entre os dois países, ao desejo de se estreitar as relaçóes de amizade e à retomada da democracia, o último proferido pela presidenta teve como marca a questáo da solidariedade brasileira e internacional, bem como a necessidade de se trabalhar para a autonomia do país. Todavia, ambos os discursos mencionaram a questão da amizade e da solidariedade como meio de atuação necessário. 


\section{Atos internacionais para a politica educacional haitiana}

A atuação no Haiti, embora condicionada a diversos elementos, resultou na manutenção de velhos acordos de cooperação e na criação de novos, dos quais, em consulta a Plataforma Concórdia ${ }^{4}$, constatou-se cinquenta resultados de pesquisa sobre o país, contendo diversos documentos relativos à saúde, segurança pública, cooperação educacional e esportiva, cooperação científica e tecnológica, agricultura, cooperação técnica, cooperação interinstitucional, direitos humanos, cooperação universitária, vistos e imigração, meio ambiente, cooperação financeira, comissão mista, energia, cooperação artística-cultural e malas diplomáticas. Muitos desses atos internacionais entraram em vigor posteriormente ao estabelecimento da Minustah e carregam em seu teor medidas que com certa densidade, estão voltadas para a reestruturação do país. Foram selecionados cinco documentos de cooperação educacional e esportiva a partir do estabelecimento da Minustah e um documento de cooperação de ensino superior.

O primeiro documento de 23 de maio de 2006 cujos signatários são Brasil e Haiti versa sobre o "Ajuste Complementar ao Acordo Básico de Cooperação Técnica entre os dois países para implementar o Projeto 'Inserção Social pela Prática Esportiva'”, um projeto cujos objetivos estão voltados para o acesso e a integração da prática esportiva na atividade educacional. Este projeto, mobilizou dos governos do Brasil e Haiti estratégias diversas para o seu cumprimento, dos quais se destacam a garantia de contribuições financeiras, definição das instituições executoras, produção de relatórios, disponibilização de infraestrutura, acompanhamento e avaliação do projeto, entre outros. Interessa pontuar que tanto a Agência Brasileira de Cooperação do Ministério das Relações Exteriores (ABC/ MRE) quanto o Ministério da Educação Nacional, Juventude e Esporte do Haiti foram designados como instituições responsáveis pela implementação e monitoramento de tal ajuste (BRASIL, 2006a). No artigo V do documento referente à execução, menciona- se que as partes contratantes poderão dispor de recursos de instituiçóes públicas, privadas, de organizações não-governamentais, de organismos internacionais, de agências de cooperação técnica, de fundos e de programas regionais e internacionais (BRASIL, 2006a).

Outrossim, ressalta-se que a primeira visita do presidente Lula ao Haiti foi marcada por um jogo amistoso de futebol entre as seleções brasileiras e haitianas,

4 Base de dados dos atos internacionais assinados pelo Brasil. Disponível em: <https://concordia.itamaraty.gov.br/>. Acesso em 12 de jun. de 2018. 
denotando a dimensão do esporte no auxilio das relações diplomáticas dispensadas pelo Brasil no período.

O segundo documento também de 23 de maio de 2006 cujos signatários são Brasil e o Banco Internacional para a Reconstrução e o Desenvolvimento (BIRD) se refere ao "Memorando de Entendimento entre o Brasil e o BIRD para Implementação da Fase II do Programa Nacional de Merenda Escolar no Haiti”. Neste é manifestado o reconhecimento e a importância da manutenção do Programa Nacional de merenda Escolar no Haiti (PNME) tanto por meio de auxílios financeiros advindos do Brasil quanto do BIRD (BRASIL, 2006b). O projeto consiste na distribuição de merenda escolar para alunos de escolas localizadas em áreas de maior vulnerabilidade social não consistindo num programa nacional, mas regional, visando tanto o incentivo das crianças à escola quanto à alimentação básica.

Evidencia-se a continuidade do Programa Nacional de Merenda Escolar (PNME) com o auxílio financeiro para o ano letivo 2006-2007 tendo como responsável o próprio PNME que é vinculado ao Ministério da Educação do Haiti. Outra questão essencial diz respeito ao fato de que após a eleição de Lula as relaçóes entre o Brasil e o BIRD se estreitaram principalmente no que se refere ao financiamento e assistência de programas sociais e para o desenvolvimento em geral. A iniciativa se assemelha aos programas sociais de políticas redistributivas desenvolvidas no Brasil durante os mandatos Lula e Dilma, todavia não contando com insumos próprios do país, mas sim com recurso de um banco internacional.

O terceiro documento de 28 de maio de 2008, cujos signatários são Brasil e Haiti condiz com o "Acordo de Cooperação Técnica no Setor Educacional entre o Governo da República Federativa do Brasil e o Governo da República do Haiti”, no qual se expóe o compromisso dos dois países em manter cooperação técnica na área educacional, com destaque para a alimentaçáo escolar, educação profissional e tecnológica (BRASIL, 2008). Neste acordo está previsto que os dois países serão os responsáveis por traçar as linhas gerais da proposta, avaliando e interrompendo o acordo se acharem necessário. As instituiçōes responsáveis pelo planejamento, coordenação e avaliação do acordo são a $\mathrm{ABC} / \mathrm{MRE}$ no Brasil e o Ministério da Educação Nacional e Formação Profissional (MENFP) no Haiti.

Neste documento foi explicitado que a execução do acordo seria decidida posteriormente e que as partes envolvidas poderiam buscar parceiros bilaterais ou multilaterais. As atividades a serem realizadas não são mencionadas, bem como os objetivos pretendidos com o acordo. Olhar para a cooperação técnica educacional é 
algo importante quando se trabalha para a reconstruçáo de um país, no entanto a redação do presente acordo não apresenta elementos necessários para identificar quais as açôes de fato foram planejadas.

O quarto documento, cujos signatários são o Brasil e o Haiti diz respeito à cooperação universitária de 25 de fevereiro de 2010, "Memorando de Entendimento entre o Governo da República Federativa do Brasil e o Governo da República do Haiti para a Reconstrução, o Fortalecimento e a Recomposição do Sistema de Educação Superior do Haiti". Tal documento expóe que "a educação é um direito humano fundamental e de que a universalização da educação superior é uma das bases para impulsionar o desenvolvimento, a soberania e a autodeterminação dos povos" (BRASIL, 2010a). E expressa a necessidade de formação de recursos humanos, de mobilidade acadêmica e reestruturação das instituições de ensino superior do Haiti em níveis de graduação e pós-graduação (BRASIL, 2010a). As instituiçôes executoras no Brasil foram a Fundação de Coordenação de Aperfeiçoamento de Pessoal de Nível Superior (CAPES), a Secretaria de Educação Superior (SESu) do Ministério da Educação (MEC) e o Ministério das Relações Exteriores (MRE) e coube ao Haiti a designação de um órgão de apoio.

Este memorando traça a cooperação entre as pesquisas desenvolvidas nos dois países como a possibilidade de intercâmbio de pesquisadores por um período de curta duração, como também apresenta a possibilidade de recursos financeiros, tais como bolsas de mestrado e doutorado para estudantes haitianos no Brasil, permitindo assim não somente o acesso, mas a permanência destes estudantes nas universidades brasileiras.

O quinto documento, em vigor, de 25 de fevereiro de 2010 cujos signatários são o Brasil e o Haiti corresponde ao "Ajuste Complementar ao Acordo Básico de Cooperação Técnica e Científica entre o Governo da República Federativa do Brasil e o Governo da República do Haiti para Implementação do Projeto 'Modernização e Fortalecimento do Centro-Piloto de Formação Profissional Brasil-Haiti'”. Este trata da implementação de um centro de referência de educação profissional no Haiti, no qual o Brasil também designa o Serviço de Aprendizagem Industrial (SENAI) como uma das instituiçóes responsáveis pelo desenvolvimento deste projeto e o governo do Haiti designa tanto MENFP quanto o Instituto Nacional da Formação Profissional (INFP) como responsáveis pelo projeto (BRASIL, 2010b).

Tal iniciativa revela a preocupação com a formaçáo profissional no âmbito do desenvolvimento industrial e, por conseguinte econômico do país. Ela também se 
assemelha ao crescimento dos Institutos Federais de Educação ocorrido nas gestóes Lula e Dilma.

O último documento de 26 de abril de 2010, em vigor, cujos signatários são o Brasil e o Haiti, diz respeito ao "Ajuste Complementar ao Acordo Básico de Cooperação Técnica e Científica entre o Governo da República Federativa do Brasil e o Governo da República do Haiti para Implementação do 'Projeto de Criação do Centro de Formação Profissional no Domínio do Comércio e dos Serviços"” (BRASIL, 2010c). Neste se amplia a oferta de educação profissional também para o comércio e serviços, almejando dentre diferentes demandas o fortalecimento da área de formação para o trato do turismo. Semelhante ao quinto documento que visava à modernização e o fortalecimento do centro de formação profissional no Haiti, esse ajuste buscou ampliar as possibilidades de formação para o emprego atendendo ao setor terciário. A partir de 2010 não se encontrou mais acordos voltados para cooperação educacional e esportiva, tampouco para a cooperação universitária disponíveis na plataforma.

Embora os atos selecionados correspondam ao campo da educação, em apenas um que diz respeito à educação superior houve a menção ao MEC. Em busca no Portal do MEC foram encontradas 10 notícias referentes ao Haiti como palavrachave, das quais 7 se referem à intervenção brasileira no país com vistas à realização de ações educacionais. As notícias circulam entre a questão da cooperação na educação profissional, na educação tecnológica, na alimentação com projetos e programa de merenda escolar, na cooperação e reestruturação de instituições de ensino superior.

Salienta-se o fato de que os atos internacionais envolvendo a educação de modo geral, esportes, alimentação e formação profissional, não tenha evidente participação do Ministério da Educaçáo Brasileiro, ou seja, de educadores brasileiros em contato com educadores haitianos, pensando formas de promover a cooperação entre os dois países.

Em consulta no site da $\mathrm{ABC}$ na seção de pesquisa foi possível encontrar o tipo de cooperação e a situação dos acordos refletidos em variados projetos, através do refinamento da busca considerando a área geográfica ou política e palavra-chave, embora nem todos apresentassem as instituições brasileiras responsáveis por sua execuçáo. Dos projetos relacionados à educação, apenas se encontra em execuçáo o Projeto de "Apoio à Educação e Formação Técnica e Profissional no Haiti, por meio 
do Estabelecimento de um Centro de Formação Profissional e Respectivo Fortalecimento Institucional", com prazo de término em 31 de dezembro de 2019.

\section{Considerações finais}

A política internacional realizada nos governos Luiz Inácio Lula da Silva e Dilma Vana Rousseff apresentou um novo panorama para as relaçóes internacionais, principalmente no que condiz com os interesses e as formas de cooperação.

No caso da Minustah, embora se apresente pontos que mereçam críticas severas, revisão e ponderação no que concerne tanto a suas razões, quanto à investida de militares e diferentes situações de violência, a missão aproximou países que mesmo mantendo determinadas relaçóes diplomáticas, não as tinham em densidade.

Os discursos do presidente Lula reforçam a questão de ambos os países terem herança africana e, por isso, serem considerados países irmáos. A questão desta semelhança no trato das origens produz a dimensão da solidariedade capaz de fomentar práticas de alteridade e empatia. Por outro lado, o neocolonialismo indica a dominação entre países da periferia em atendimento às dinâmicas do centro, o que pôde refletir em determinadas práticas do Brasil em relação ao Haiti.

Outro ponto importante se refere ao fato de que nos discursos apresentados, a busca pela reconstrução do Haiti e pelo retorno de sua soberania nacional se fez evidente. No caso da presidenta Dilma Rousseff, há duas considerações importantes sobre este aspecto, primeiro a questão da missão de paz para a proteção e não para opressão e a segunda diz respeito a projeção futura de que o Haiti se restabeleça e conte com suas próprias instituições para atuar no país.

Não se pode ignorar o fato de que a Minustah foi utilizada como uma "bandeira" da atuação internacional brasileira, como também não se pode desconsiderar que o atendimento emergencial ao Haiti, alguns atos de cooperação e, ainda o visto em caráter humanitário, trouxeram fôlego para o país que vivenciava, para além de uma história marcada por anos de subjugo político e econômico, inclusive de países membros da Organização das Nações Unidas (ONU) como França e os Estados Unidos da América, diferentes catástrofes climáticas que levaram milhares de pessoas a óbito.

No caso do governo Michel Temer, a ausência de um discurso presidencial revela questôes importantes tanto no que diz respeito à política externa desenvolvida nessa gestão quanto à invisibilidade de um país e de um povo que firmaram acordos recentes para a cooperação e a solidariedade. 
Conclui-se que a alteridade entendida como percepção e respeito ao outro requer para além de um exercício reflexivo, a criação de estratégias que possibilitem a emancipação, pois ser solidário verdadeiramente inclui compreender a importância da plenitude, dos direitos e da dignidade para todos.

- Daniela Dos Santos Caetano é Mestranda no Programa de PósGraduação da Faculdade de Educação da Unicamp na linha Estado, Políticas Públicas e Educação. Formada em Letras pela UNESP. Especialista em Ética, Valores e Cidadania na Escola pela USP e Professora Adjunta de Língua Portuguesa pela SMECampinas. E-mail: danielascaetano@mail.com.

Sandra Fernandes Leite é Doutora em educação pela Universidade Estadual de Campinas (2009 -2013) na área de concentração de Políticas, Administração e Sistemas Educacionais, com foco de estudos na modalidade de Educação de Jovens e Adultos. Professora do Programa de Pós-graduação da Faculdade de Educação da Unicamp e Coordenadora do Comitê Ética em Pesquisas em Ciências Humanas da Unicamp. E-mail: sanferleite@gmail.com.

\section{Referências}

ABBAGNANO, Nicola. Dicionário de Filosofia. 5 ed. São Paulo: Martins Fontes, 2007.

BRASIL. Ministério da Educação. Portal do MEC. Disponível em: $<$ http://portal.mec.gov.br/?params[search_relevance]=haiti\&task=search\&option=com_content\&vie $\mathrm{w}=$ buscageral\&params[search_method] $=$ all\&params $[$ ord $]=$ pr\&Itemid=30188>. Acesso em: 04 maio 2018.

Ministério das Relaçóes Exteriores. República do Haiti [online]. Disponível em: $<$ http://www.itamaraty.gov.br/index.php?option=com_content $\&$ view=article \&id=5221 \&Itemid=47 8\&cod_pais=HTI\&tipo=ficha_pais\&lang=pt-BR>. Acesso em 09 de dez. de 2017. 
Plataforma Concórdia. Ajuste Complementar ao Acordo Básico de Cooperação Técnica entre o Brasil e o Haiti para Implementar o Projeto "Inserção Social pela Prática Esportiva. 23 de maio de 2006. Diário Oficial da União, Brasília, DF, n. 105, 2 jun. 2006 a. Seção 1, p. 54- 55.

Plataforma Concórdia. Memorando de Entendimento entre o Brasil e o BIRD para Implementação da Fase II do Programa Nacional de Merenda Escolar no Haiti. 23 de Maio de 2006. Diário Oficial da União, n. 105, 2 jun. 2006b. Seção 1, p. 52.

. Plataforma Concórdia. Acordo de Cooperação Técnica no Setor Educacional entre o Brasil e o Haiti. 28 de Maio de 2008. Diário Oficial da União, Brasília, DF, n. 132, 11 jul. 2008. Seção 1, p. 57.

Plataforma Concórdia. Memorando de Entendimento entre o Governo da República Federativa do Brasil e o Governo da República do Haiti para a Reconstrução, o Fortalecimento e a Recomposição do Sistema de Educação Superior do Haiti. 25 de Fevereiro de 2010. Diário Oficial da União, Brasília, DF, n. 60, 30 mar. 2010a. Seção 1, p. 126.

- Plataforma Concórdia. Ajuste Complementar ao Acordo Básico de Cooperação Técnica e Científica entre o Governo da República Federativa do Brasil e o Governo da República do Haiti para Implementação do Projeto "Modernização e Fortalecimento do Centro-Piloto de Formação Profissional Brasil-Haiti”. 25 de fev. de 2010. Diário Oficial da União, Brasília, DF, n. 59, 29 mar. 2010b. Seção 1, p. 64.

- Plataforma Concórdia. Ajuste Complementar ao Acordo Básico de Cooperação Técnica e Científica entre o Governo da República Federativa do Brasil e o Governo da República do Haiti para Implementação do "Projeto de Criação do Centro de Formação Profissional no Domínio do Comércio e dos Serviços”. 26 de Abril de 2010. Diário Oficial da União, Brasília, DF, n. 220, 18 nov. 2010c. Seção 1, p. 72.

CARVALHO, Amanda Sanches Daltro; ROSA, Renata de Melo. nome por extenso dos autores. O Brasil e a não-indiferença à crise haitiana: solidariedade ou retórica do discurso? Univ. Rev. Int., v. 9, n. 1, p. 487- 509, 2011.

FRANCO, Maria Ciavatta. Quando nós somos o outro: questôes teórico-metodológicas sobre os estudos comparados. Educação \& Sociedade, v. 21, n. 72, 2000.

JAMES, Cyril Lionel Robert. Los Jacobinos Negros. Toussaint L'Ouverture y la Revolución de Haití. Madrid, Ed. Turner, 2003.

KENKEL, Kai Michael. Interesses e Identidades na participação do Brasil em Operações de Paz. Revista Tempo do Mundo, v. 3, n. 2, 2011.

LÜDKE, Menga; ANDRÉ, Marli Elisa Dalmazo Afonso De. Pesquisa em Educação: abordagens qualitativas. São Paulo: EPU, 1986.

MILANI, Carlos Roberto Sanchez. Aprendendo com a História: críticas à experiência da Cooperação Norte-SUL e atuais desafios à Cooperação SUL-SUL. Caderno CRH, v. 25, n. 65, p. 211-231, 2012.

MIYAMOTO, Shiguenoli. As Grandes Linhas da Política Externa Brasileira. Brasília: CEPAL. 2011. NUNES, Raul Cavedon; RODRIGUEZ, Vitória Gonzalez. A Política Externa Brasileira de TemerSerra: retração política e subordinação econômica. Boletim de Conjuntura NERINT. Porto Alegre, v. 1, n. 4, p. 1-9, 2017. 
ORGANIZAÇÃO DAS NAÇÕES UNIDAS. Conselho de Segurança. Resolução 1542. 2004. Disponível em: <http://www.un.org/en/ga/search/view_doc.asp?symbol=S/RES/1542\%282004 \%29>. Acesso em: 12 dez. 2017.

ORGANIZAÇÃO DAS NAÇÓES UNIDAS NO BRASIL. CEPAL [online]. Disponível em: <https://nacoesunidas.org/agencia/cepal/> Acesso em: 09 dez. 2017.

ORLANDI, Eni P. Análise de discurso: princípios e procedimentos. 6. ed. Campinas: Pontes, 2005.

PÊCHEUX, Michael. O Discurso: estrutura ou acontecimento. 4. ed. Campinas: Pontes, 2006.

PENNAFORTE, Charles. A Política Externa Brasileira Pós-Impeachment: mudança ou estagnação? In: XVI Congresso Internacional FOMERCO. Integração Regional em Tempos de Crise: desafios políticos e dilemas teóricos. Salvador: 26- 29 set. 2017.

PROSPERE, Renel; NOGARO, Arnaldo. Educação e Transformação Social no/ do Haiti: à luz (da Pedagogia Braçal) de Frantz Fanon. Campinas: Mercado das Letras, 2017.

ROUSSEFF, Dilma Vana. Discurso da Presidenta da República, Dilma Rousseff, durante cerimônia de apresentação do contingente brasileiro da Missão das Naçóes Unidas para a Estabilização do Haiti. Ministério das Relaçóes Exteriores. Resenha de Política Exterior do Brasil, v. 37, n. 110, 2012. Disponível em: <http://www.itamaraty.gov.br/images/ed_biblioteca/resenhas_peb/ resenha110_1Sem_2012.pdf>. Acesso em: 13 dez. 2017.

SÁ, Jéssica Espíndola de. A Decisão Brasileira de Participar da Minustah. 2015. 142 f. Dissertação (Mestrado em Relaçóes Internacionais). Universidade Estadual da Paraíba, Centro de Ciências Biológicas e Sociais Aplicadas, João Pessoa. 2015.

SÁ-SILVA, Jackson Ronie; ALMEIDA, Cristóvão Domingos de; GUINDANE, Joel Felipe. Pesquisa documental: pistas teóricas e metodológicas. Rev. Bras. Hist. Cienc. Soc., v. 1, n. 1, p.1-15, 2009.

SEGUY, Franck. Para Compreender a Recolonização do Haiti. Revista Outubro, n. 22, 2014.

SILVA, Luiz Inácio Lula da. Missão de Paz no Haiti. Ministério das Relaçóes Exteriores. Resenha de Política Exterior do Brasil, v. 31, n. 94, 2004a. Disponível em: <http://www.itamaraty.gov.br/images/ed_biblioteca/resenhas_peb/Resenha_N94_1Sem_2004.pdf>. Acesso em: 13 dez. 2017.

. A Visita do Presidente da república ao Haiti. Ministério das Relaçóes Exteriores. Resenha de Política Exterior do Brasil, v. 31, n. 95, 2004b. Disponível em: <http://www.itamaraty.gov.br/images/ed_biblioteca/resenhas_peb/Resenha_N95_2Sem_2004.pdf>. Acesso em: 13 dez. 2017.

- Discurso do Presidente da República, Luiz Inácio Lula da Silva, perante a Brigada Brasil da Missão das Naçóes Unidas para o Haiti, em Porto Príncipe, Haiti, em 18 de agosto de 2004. Ministério das Relaçóes Exteriores. Resenha de Política Exterior do Brasil, v. 31, n. 95, 2004c. Disponível em: <http://www.itamaraty.gov.br/images/ed_biblioteca/resenhas_peb/Resenha_N95_ 2Sem_2004.pdf>. Acesso em: 13 dez. 2017.

Cerimônia de honras fúnebres aos militares mortos no cumprimento do dever na Missão de Paz no Haiti. Ministério das Relaçóes Exteriores. Resenha de Política Exterior do Brasil, 37, n. 106, 2010a. Disponível em: <http://www.itamaraty.gov.br/images/ed_biblioteca/resenhas_peb/ resenha106_1_2010.pdf>. Acesso em: 13 dez. 2017.

. Cerimônia de formatura das tropas brasileiras da Missão da ONU no Haiti (Minustah). Ministério das Relaçóes Exteriores. Resenha de Política Exterior do Brasil, 37, n. 106, 2010b. 
164 | Daniela Dos Santos Caetano e Sandra Fernandes Leite

Disponível em: <http://www.itamaraty.gov.br/images/ed_biblioteca/resenhas_peb/ resenha106_1_2010.pdf>. Acesso em: $13 \mathrm{dez} .2017$.

Texto recebido em 06 de agosto de 2018. Aprovado em 05 de novembro de 2018. 